\title{
An analysis of increased usage of e-commerce during COVID-19
}

\author{
Abdulmohsin Suliman Alkhunaizan ${ }^{1}$, Ashraf Ali ${ }^{2}$ \\ ${ }^{1}$ Department of Information Systems, College of Computer Science, Majmaah University, Majmaah, Saudi Arabia \\ ${ }^{2}$ Faculty of Computer Studies, Arab Open University, A'ali, Kingdom of Bahrain
}

\begin{tabular}{l} 
Article Info \\
\hline Article history: \\
Received Jul 27, 2021 \\
Revised Nov 20, 2021 \\
Accepted Dec 1, 2021 \\
\hline
\end{tabular}

Keywords:

COVID-19

E-commerce

Mobile pay

\begin{abstract}
Technolgoical innovation has covered all aspects of business all over the world. With growing pace of digitalisation all over the globe, e-commerce has become one of the popular platforms for initiating business transactions. COVID-19 has showed the dependence of the society on this medium for the convenient allocation of goods and services and meeting up of consumer demands. Saudi Arabia has also witnessed a high demand in the usage of this platform to meet the daily usage necessity. In order to get insight into the topic, qualitative research has been undertaken. The study aims to investigate the increased use of e-commerce during COVID-19. The data required for the analysis has been collected from secondary sources such as web journals and research work. The finding of the qualitative analysis exhibited that the e-commerce has increased rapidly during COVID-19 time. The outcomes of the present study are helpful for the vendors to facilitate the consumers by increasing the opportunities of e-commerce.
\end{abstract}

This is an open access article under the CC BY-SA license.

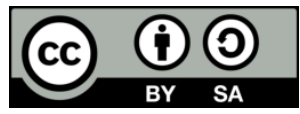

\section{Corresponding Author:}

Ashraf Ali

Faculty of Computer Studies, Arab Open University

A'ali, Kingdom of Bahrain

E-mail: ashraf.ali@aou.org.bh

\section{INTRODUCTION}

The ease of technology has impacted the way instruction form language learning [1]-[4] to shopping [5]. The $21^{\text {st }}$ century has witnessed a lot of changes in society and work culture all over the world. One of the changes which we all are witnessing, acknowledging and adapting is the change in the concept of buying and selling with respect to the platform of the market. In this current century, we have witnessed a shift of buying and selling platforms from the traditional physical form to the modern platform of e-commerce [6]. Modern shopping malls are undeniably a beehive of tremendous shopping activity [7], [8]. E-commerce is understood as the purchase and sale of goods and services over the online platform. The amalgamation of various automated data systems facilitates buying and selling over the online platform. The share of e-commerce in total global retail sales is approximately $21.8 \%$ [9]. The e-commerce platform is being used all over the world, but in the Gulf Cooperation Council region, Saudi Arabia has an e-commerce market size of 9.8 billion U.S dollars, making it the largest e-commerce industry in the Gulf region [9].

Because of the COVID-19 financial crisis, e-commerce has expanded rapidly to include new sorts of businesses, customers, and items. A wide range of items are available to customers from the comfort of their own homes, and companies are able to continue operating despite contact limitations and other confinement measures. Contrary to popular belief, the COVID-19 issue has improved the dynamic of the e-commerce environment across nations and broadened the reach of e-commerce to include new enterprises, consumer segments, and products. While this is happening, in many nations, e-commerce transactions are shifting away from luxury items and services and toward essentials that are important to a huge number of people. Due to new waves of epidemics, the convenience of new purchase habits, learning costs and enterprises' incentives 
to capitalise on investments in new sales channels, some of these e-commerce landscape changes will likely be long-term in character.

This paper aims to analyse the increased usage of e-commerce during the COVID-19 pandemics in Saudi Arabia. A special focus has been given to the mobile payment mode of transaction for the purpose of buying and selling. The paper has also highlighted the various literature papers available on this topic. The paper further focuses on the methods and data analysis of the concerned topic. Findings, discussions and implications are further discussed in the paper.

\section{LITERATURE REVIEW}

The term e-commerce was first coined by Dr. Robert Jacobson in the year 1984. However, in the year 1972, Advanced Research Projects Agency Network (ARPANET) was first used as a seminal act of ecommerce. Since 1972, the world has been witnessing a strong development of the e-commerce business, and various multinational business houses and organisations have been providing their products and services for sale through this platform. E-commerce is divided into three categories, i.e., consumer to consumer (C2C), business to consumer (B2C), and business to business (B2B). From both consumers and business houses points of view, e-commerce has the utmost importance in their daily work progress. The business of ecommerce strongly depends on supply chain management, electronic fund transfer, and online mode of transaction, electronic data transfer and automated data collection systems [10]. The ease and convenience associated with the online purchase and selling of products and services make e-commerce more demanding for both buyers and sellers. For entrepreneurs and sellers, e-commerce is considered to be a golden opportunity to make their business more approachable, successful and powerful. In this digital world, a business house can sustain itself in the competitive market with the usage of E-commerce and networking. As far as the consumers are concerned, it can be said that the e-commerce platform provides a wide range of goods and services to the customers available on a single platform; it is more convenient and timesaving to sit and shop at home rather than hop to malls. Adequate information regarding the product is easily available on the websites of e-commerce which makes it even more trustworthy. These features make e-commerce appealing for both consumers and producers in all situations and scenarios.

The features of e-commerce make it appealing for both consumers and producers in all situations and scenarios [11]. However, in the recent pandemic situation, it was noticed that the e-commerce business expanded and flourished like never before. The crisis and inconvenience due to the pandemic made us realise the increased dependency on the e-commerce business. Many new and existing firms realised the potential of e-commerce and started giving their services using this platform [12]. The customers who were earlier not very used to the online mode of buying and selling realised the utility and convenience which this platform provides. The online medium of buying and selling has provided access to products and services to the consumers during the lockdown situation prevalent across the globe during the pandemic, especially in the year 2020 [13]. The business firms could also continue with their business operation with the online medium during the curtailment situation [14]. It was because of the online platform of e-commerce that many business houses could survive in the market even with low demand. However, due to the digital divide, a large population was not able to use this platform to meet their demand for products and services. Customers faced challenges relating to network connectivity, digital and data security, privacy and financial constraints for availing the services of e-commerce.

The COVID-19 pandemic has caused us to engage in novel social behaviour [15], [16]. With the outbreak of the virus, curbs and restrictions were put across the borders of the country, and this resulted in a significant shift in consumer behaviour in Saudi Arabia. The citizens of the country turned towards the usage of digital platforms and channels to fulfil their demands for goods and services. Companies operating within the territories of the country witnessed a significant boost in their e-commerce business [17]. The positive impact of the increased sales was that the company was able to retain the employees and even hired more packers and movers in order to fulfil the increased demand. In the same way, the grocery delivery app Nana benefitted from the online platform of e-commerce during the pandemic and raised 18 million dollars fund and expanded its business in Middle East countries [18], [19]. The retail sectors of the country witnessed significant growth during the pandemic, and to sustain this growth, the government of Saudi Arabia has ensured long term sustainability in this sector [20]. The government of Saudi Arabia implemented Ecommerce Law to improve digital transparency and regulation [21]. The regulations of the e-commerce law are implemented with an insight to increase personal data protection, consumer rights and disclosure rules. To achieve the growth targets of the country by the year 2030, digital occupancy and services are seen as the key players [22]. The government is upgrading the digital services in the priority sectors of the country with a special focus on health services and digital education to senior citizens. To achieve digital excellence, the country is focussing on empowering the private sectors in initiating digital projects in the country [23]. 
The business of e-commerce uses technologies such as mobile commerce and payment, electronic fund transfer, internet banking, online transaction processing and many more [24]. The e-commerce payment system facilitates an electronic payment facility for all types of the online transaction. Mobile payment is a medium or mode of payment for goods and services using portable devices such as mobile phones, tablets or palmtops [25]. The technology of mobile payment enables users to send and receive money payments via particular payment applications installed on the phone. Payments made for buying and selling of products through mobile payment applications are more famous in Asian and European countries. Payments through mobile are considered to be more safe and secure than payments made through physical cards as it provides additional privacy and safety measures. The data regarding the payment is encrypted and destination-specific during the payment. Mobile payment via PayPal, AliPay, and WeChat Pay, have gained worldwide popularity [26]. The prime benefit which can be associated with mobile payments is the elimination of physical wallets. The facility of mobile payments has been effective in saving the time of the consumers. The government of Saudi Arabia approves payment through various online e-payment portals. Some of the epayment portals are Moyasar, Payfort, Paytabs and Hyperpay. The electronic payment software's and applications as approved by the government are STC Pay, Bayan Pay, Mada Pay and Apple Pay [26]. The country has witnessed a rise in the number of internet users over the years. In 2015, 15 million of the population was using internet whereas in the year 2020, 30.44 million was using the service [27].

\section{METHODS}

Secondary research method was employed to collect the data for the present study. Secondary information can be acquired from existing studies or by conducting new ones using secondary data that has previously been gleaned from those studies. It saves both time and is cost-effective [28]. A systematic approach followed to obtain totally new and reliable information and knowledge on a particular topic is understood as research. From the above discussion, it becomes clear that in-depth research and study must be carried out in order to ascertain and analyse the usage of e-commerce during the pandemic with specific relevance to mobile payment methods used in Saudi Arabia. In order to get insight into the topic, qualitative research has been undertaken.

The data required for the analysis has been collected from secondary sources such as web journals and research work. The focus of the analysis has been limited to the examples and conditions related to the country Saudi Arabia. However, for a global comparison of the usage of e-commerce platforms and mobile payment methods, the data related to many other countries have also been considered. Various statistical tables, facts and figures have been considered for making a final conclusion on the topic of discussion. Obligations of ethical parameters are essential for carrying out any research work in any field and on any topic. The ethical parameters have been very well maintained while carrying out the research work on this topic. Data analysis is important for research as an analyst looks through the primary analysis elements of critical thinking ideas, hypotheses, and conceptions that frequently arise. Researchers utilise statistical research analysis to reduce data to a story and evaluate it in order to gain insights. It aids in the discovery of codes and themes in data, allowing for easier recognition and linkage [29]. Thematic analysis is a type of data analysis that entails looking over a group of statistics such as recordings through interviews and observations and finding patterns within the interpretation. In the subject of psychiatry, thematic analysis is commonly employed [30]. Thematic analysis aids in accurately forecasting product demand.

The use of illustrations to obtain findings is known as graphic data analysis. Graphs are really a popular way to visually represent system behaviour. The objective of a graph is to convey data that are too complex to be fully expressed in prose and in a limited space [31]. Graphical analysis helps to display a company's development, connection and trends. It also assists management and decision-makers in making statistics-driven decisions. A process of evaluating, categorising, interpreting, and synthesising data is statistical data analysis. To assist firms in making educated decisions, businesses administration experts create conclusions about products, marketplaces, and clients from various data sets. The thematic study provided a very practical approach that may be changed for the demands of numerous investigations, delivering a thorough and complex yet complicated description of data due to its conceptual flexibility. One of the numerous advantages of theme analysis is that this is a method of e-commerce study in Saudi Arabia that is available to beginning [32] researchers who are really beginning to collect qualitative data. Because thematic analysis is such a versatile method, there are many possible ways of interpreting the information set's significance.

\section{DATA ANALYSIS}

This paragraph summarises the current state of Saudi Arabia's population and technology, as well as how they pertain to a country's potential growth in e-commerce usage. The Country's e-commerce overall 
market is bolstered by its status as the Arab World's capital, with the wealthiest nation. Around $90 \%$ of the population also had internet connectivity in 2020. These characteristics facilitated e-commerce growth among many of the populace, with over $80 \%$ of online users throughout Saudi Arabia online purchases, the same percentage as it is in China [33]. As a result, the Arab continent's e-commerce business has been one of the biggest, and it is inclined to continue to develop. Furthermore, internet access in the area has increased rapidly in recent years, including prevalence in the other parts of Saudi Arabia, including the United Arab Emirates topping $90 \%$. Their existing internet prevalence rate in the country is $60 \%$, which is significantly higher than the world average of $51.7 \%$ [34]. The coronavirus outbreak prompted "significant" improvements throughout the e-commerce industry. The surge in the coronavirus prevented individuals in Saudi Arabia from going to traditional markets and forced them to buy products online, giving a boost to e-commerce.

\subsection{Changing patterns in Saudi Arabia}

Although the COVID-19 outbreak has wreaked havoc on businesses, e-commerce has already exploded. Saudi Arabia was also no exception to the global pattern, with e-commerce purchases anticipated to increase in the coming years [34]. It is unsurprising that the epidemic has had an influence on Saudi consumer preferences. The local consumer industry is already on the edge of a digital revolution, with industry participants transitioning from a conventional in-store model to an online platform using digital technology. Not just did e-commerce increase sales dramatically, but it also did whatever was purchased. In Saudi Arabia, people who previously used digital platforms to purchase clothing, cosmetics, and electronics, now use the internet to shop for groceries and household items. Due to apprehension over online transactions, the people of Saudi Arabia were forced to rely on cash on delievery (COD) until 2020 [33]. Customers were obliged to abandon their habit of using COD and settle for even a digital payment method as a result of COVID-19 and societal distancing conventions. This demonstrates a Newfound trust in the e-commerce industry, as even more people of Saudi Arabia have purchased online than before. Figure 1 describes the changing shopping patterns in Middle East.

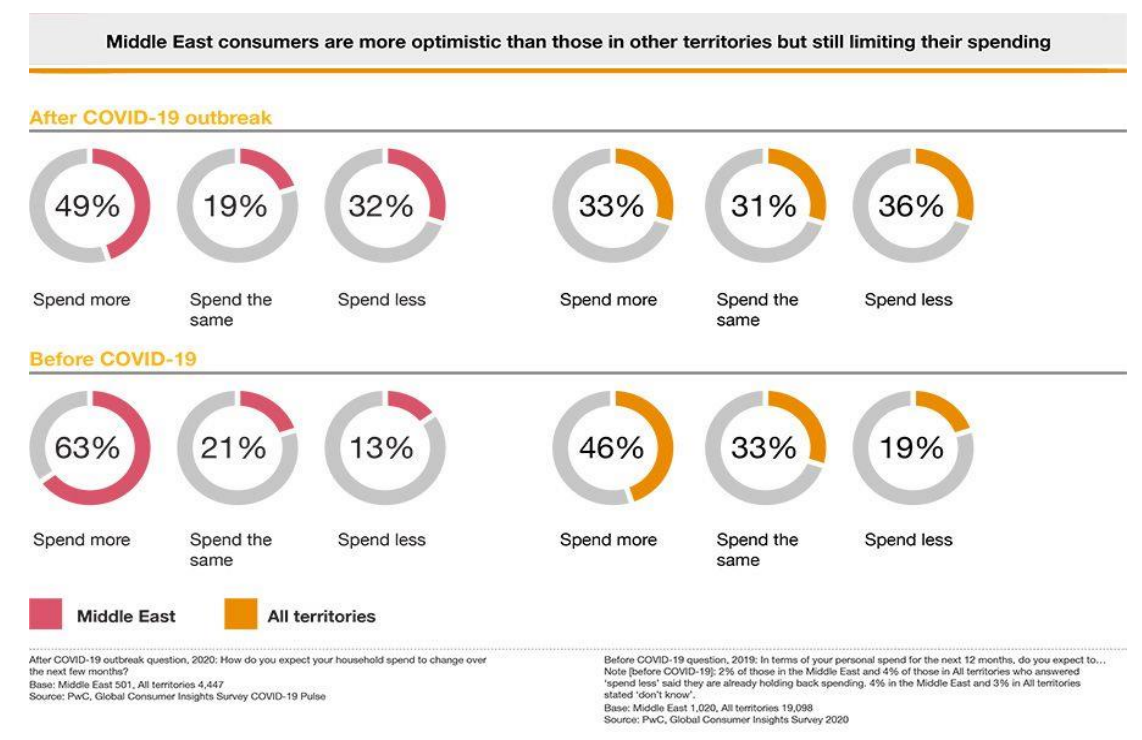

Figure 1. Changing shopping patterns in Middle East [35]

\subsection{Demand pattern in Saudi Arabia}

Saudi Arabia has experienced a surge in e-commerce retail in recent years. The retail industry is expanding, fuelled by a younger generation with an average age of just 29 years. One of the main beneficiaries of Saudi Arabia's internet commerce growth is fashion [36]. Despite restricted social conventions dictating dress and look, desire and intention are prospering in men's and women's fashion, outerwear, shoes, and cosmetics. Shien witnessed a significant increase in demand and is among the most sought-after brands. Cost, variety, comfort and accessibility all played a role in success. According to recent data, buyers in Saudi Arabia reportedly dramatically increased the overall e-commerce of food items in the aftermath of the COVID-19 epidemic. Figure 2 describes the top e-commerce platforms of Saudi Arabia. 
In Saudi Arabia, internet sales revenue has been steadily expanding. The data explains that Namashi.com was the highest in generating the revenue, which was 126 million in 2020. This is followed by the Jarir.com and Amazon.com. Even though the lowest sale (51 million) is also significant. This is a clear indication of the assertion that e-commerce is expanding during the recent years. Figure 3 describes the ecommerce revenue and forecasts in Saudi Arabia.

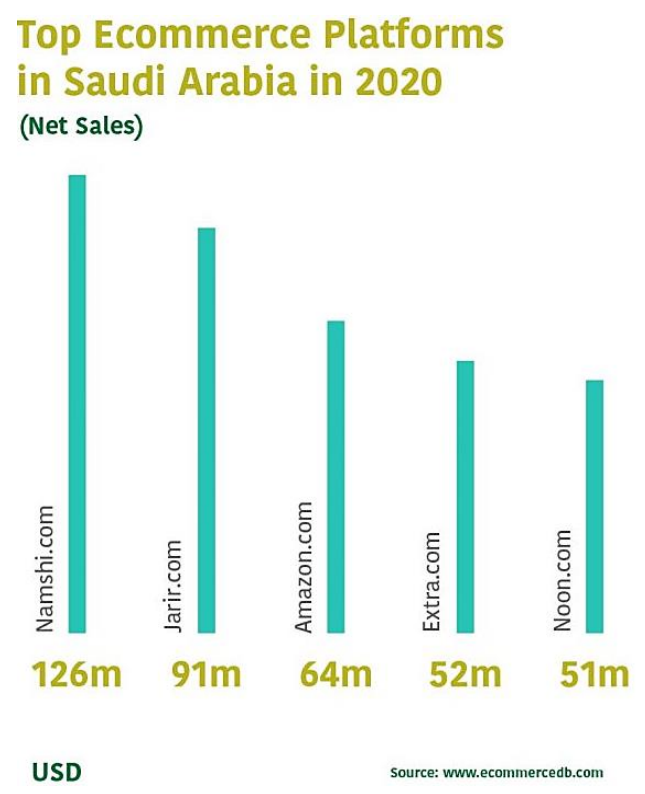

Figure 2. Top e-commerce platforms of Saudi Arabia [36]

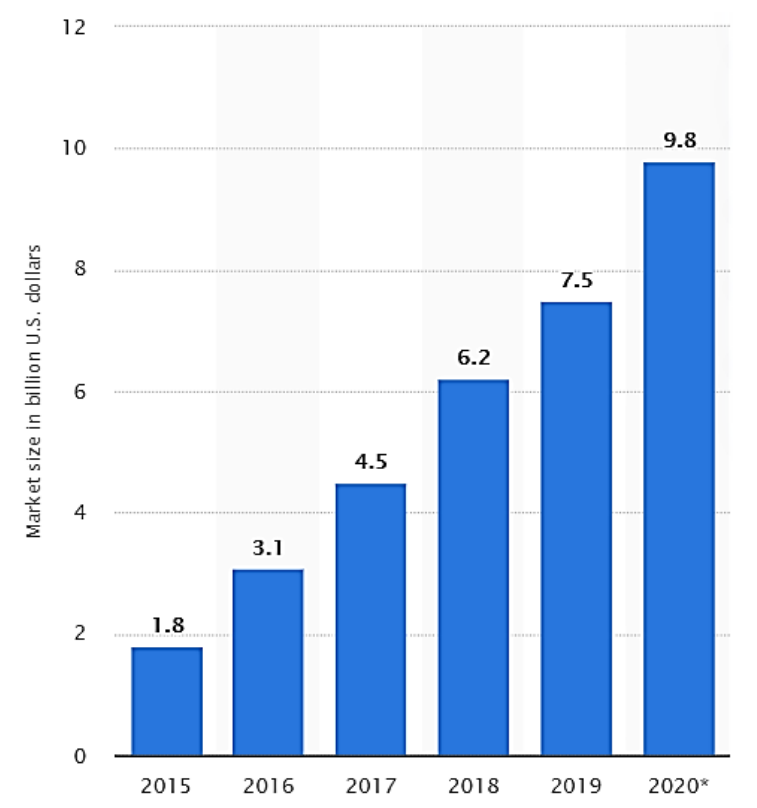

Figure 3. Ecommerce revenue and forecasts in Saudi Arabia

The e-commerce market generated 6,360 million dollars in revenue. In the years 2018-2023, revenue is predicted to expand at a $9.8 \%$ yearly rate. In 2019, the e-commerce company had a market valuation of around 4.9 million dollars. The e-commerce business was predicted to develop at a steady pace through 2024 when it was projected to increase 8 billion dollars in revenue [37]. Buyers' acclimation to ecommerce was aided by the constraints imposed by the COVID-19 epidemic [38]. Clothes, as well as electronic products and entertainment, led the online sector in 2015 with the perfect upcoming in last because most of the consumers prefer to buy groceries in the physical market. This pattern is likely to grow in the future. Airlines are the most popular in the UAE, followed by apparel and footwear, electronic products, and entertainment.

\section{DISCUSSION AND IMPLICATIONS}

This section surprises the state of the Saudi Arab population in the economy as well as how they relate to the kingdom's rise in e-commerce uses in COVID-19. In Saudi Arabia, the COVID-19 problem has expedited the growth of e-commerce to new enterprises, consumers, and merchandise kinds. It has given clients access to a wide range of commodities from both the safety and comfort of their own houses, and it has allowed businesses to keep functioning despite contact limits and other constraints. Because of the prospect of fresh surges of a virus, the comfort of new purchase patterns, training costs, and the motivation for businesses to benefit from investing in infrastructure distribution channels, a few of these developments inside the e-commerce environment will most certainly be lengthy. In Saudi Arabia the impact of the COVID-19 situation on e-commerce is not constant among market segments or vendors [39]. Although the Kingdom's relatively little health effect, the threat posed by a COVID-19 virus-combined with attempts to keep a social distance-has resulted in a considerable change in living and consumption patterns, with ecommerce seeing a tremendous rise. Until recently, e-commerce has seen a significant improvement in the service [40], [41] it provides to clients in Saudi Arabia. As it increasingly emphasises development rather than just purchasing decisions.

Customers' opinions of the amount with which effective level with which a legitimate rival option, such as e-commerce, is accessible to do shopping is known as observed lack of choice. A person will choose 
one of the current alternatives owing to the accessibility of multiple possibilities. Competitive options are accessible in the market and are referred to as an apparent lack of choice [42]. In the wake of the coronavirus pandemic, e-commerce has radically changed the face of customer behaviour in commercial business models, as well as other sectors around the world. Several components influence desirability as an e-commerce investment location, including high disposable incomes, well-developed logistics, plus elevated amounts of internet adoption. There's been a tendency for digitisation in recent years, which has been dramatically pushed by the epidemic. New technologies have altered old procedures in practically every industry, as well as customer attitudes and behaviours. E-commerce has indeed risen inside the area as a result of the province's high social media usage. Technology is more important than ever before in guaranteeing that all aspects of development can flourish. This pandemic's influence on consumer behaviour indicates a considerable increase in e-commerce, a shift in purchase behaviour, and a reduction in consumption spending [43], [44]. In terms of e-commerce, Saudi Arabia is thriving, and it is the world's largest and fastest-growing market. In the wake of the epidemic, domestic e-commerce saw a significant growth in the use of digital payment channels the kingdom. Using contactless payment methods in online marketplaces and retailers has not only become necessary, but it has also reduced the spread of COVID-19 through those channels. Contactless debit and credit cards have become more popular as a result of this trend, especially in nations where the use of these technologies is widespread.

\section{CONCLUSION}

As a result of rapidly changing customer behaviour, the Saudi Arabia E-commerce sector has grown significantly in recent years. The local e-commerce business is at crossroads, and huge prospects awaits as investors from many industries come together. To address the market's difficulties, various aspects of the environment are beginning to collaborate. As per the UNCTAD report, this COVID-19 epidemic has led to high prices for prominent B2C e-commerce enterprises. During the crisis period, for instance, elderly people who began using e-commerce to increase physical distance may continue to follow their recently bought patterns in proportion. E-commerce is increasingly a critical alternative and complementary marketing plan for many businesses, allowing them to continue operating despite interaction limitations as well as other restrictions. The COVID-19 situation is hastening the growth of e-commerce to business entrants, consumers, and kinds of goods, implying a shift in e-commerce activities beyond goods and services to common essentials, according to this short. It also shows how regulators might take advantage of the promise of digital revolution in the retail industry.

A wide variety of options for payments by the retail business units can cater to the demands of a large group of customers. The youngsters form a large unit or share in the shopping of goods and services, and in spite of carrying cash or cards, they prefer to use online payment methods to purchase items. Customers consider online payment to be safe and secure as compared to the traditional card payment methods because the online payment software's is encrypted, technologies like SSL and PCI DSS are used to secure the payment transactions. Hackers find it difficult to hack the data and information stored in the payment portals. Integration of mobile payment solutions and security features have enabled us to meet the blues of the pandemic and quarantine in an efficient, safe and convenient way. The facilities of e-commerce can be benefited from the upgrading of the mobile patent features in the near future.

Policymakers should continue to nurture the enabling environment for online transactions in areas like digital connection, (international) logistics, and trade, including digital products and services, in order to create an effective e-commerce ecosystem that delivers for all. Postal services, for example, have a direct impact on e-commerce. Moreover, the use of mobile based payment can make e-payment easy and efficient. E-payment can also be operative for smart transit transportation. E-payment may also be helpful for reducing the possibility of the spread of certain virus such as COVID-19. In many countries, logistics and transhipment have slowed as a result of new COVID-19 safety requirements and government recommendations, but the fact that they were regarded important industries by many governments has assisted in their retention as key supply-side enablers of e-commerce. As a result, service providers in various countries are promoting contact-free delivery solutions like parcel lockers or replacing signatures with other forms of evidence of delivery in order to encourage customers to switch. Governments have a role to play in promoting these kinds of initiatives. This could include expanding the coverage of parcel locker networks or encouraging more efficient locker usage, such as by enhancing interoperability or sharing between different service providers.

\section{REFERENCES}

[1] A. S. Alkhunaizan and R. M. I. Khan, "The Use of M-Learning: A Perspective of Learners' Perceptions on M-Blackboard Learn," International Journal of Interactive Mobile Technologies, vol. 15, no. 2, pp. 4-17, 2021, doi: 10.3991/ijim.v15i02.17003. 
[2] R. Khan, N. Radzuan, M. Shahbaz, and A. Ibrahim, "EFL instructors' perceptions on the integration and implementation of MALL in EFL classes," International Journal of Language Education and Applied Linguistics, vol. 08, no. 2, pp. 39-50, 2018.

[3] R. M. Ishtiaq Khan, N. R. M. Radzuan, S. U. H. Farooqi, M. Shahbaz, and M. S. Khan, "Learners' perceptions on WhatsApp integration as a learning tool to develop EFL vocabulary for speaking skill," International Journal of Language Education, vol. 5, no. 2, pp. 1-14, 2021, doi: 10.26858/ijole.v5i2.15787.

[4] Muhammad Shahbaz and Raja Muhammad Ishtiaq Khan, "Use of Mobile Immersion in Foreign Language Teaching to Enhance Target Language Vocabulary Learning," MIER Journal of Educational Studies Trends \& Practices, pp. 66-82, 2021, doi: $10.52634 / \mathrm{mier} / 2017 / \mathrm{v} 7 / \mathrm{i} 1 / 1448$

[5] A. F. Fadzil et al., "entrepreneurial psychology and competencies: some perspectives from e-commerce entrepreneurs in Malaysia Introduction Recently, there are many debatable issues discussed in areas of entrepre- neurship research . Variety opinions are also identifiable wi," Journal of Entrepreneurship, Business and Economics, vol. 7, no. 2, pp. 31-79, 2019.

[6] V. Svatosova, "The importance of online shopping behavior in the strategic management of e-commerce competitiveness," Journal of Competitiveness, vol. 12, no. 4, pp. 143-160, 2020, doi: 10.7441/joc.2020.04.09.

[7] L. Sanny, T. D. Julianto, S. Savionus, and B. W. bin Y. Kelena, "Purchase intention in the fashion industry on local and international E-commerce in Indonesia," International Journal of Asian Business and Information Management, vol. 13, no. 2, pp. 1-12, 2022, doi: 10.4018/IJABIM.20220701.0a4.

[8] H. Bello-Salau, A. J. Onumanyi, D. Michael, R. Isa, C. O. Alenoghena, and H. Ohize, "A new automated smart cart system for modern shopping centres," Bulletin of Electrical Engineering and Informatics, vol. 10, no. 4, pp. 2028-2036, 2021, doi: 10.11591/EEI.V10I4.2762

[9] Statista Research Department, E-commerce market size in Saudi Arabia from 2015 to 2019 with forecasts for 2020 (in billion U.S dollars), Statista, 2021. Accessed: June 15, 2021. [Online]. Available: https://www.statista.com/statistics/1201920/saudi-arabia-ecommerce-market-size/

[10] A. Kwilinski, "Implementation of blockchain technology in accounting sphere," Academy of Accounting and Financial Studies Journal, vol. 23, no. Special Issue 2, pp. 1-6, 2019.

[11] R. Alves, R. da S. Lima, D. C. de Sena, A. F. de Pinho, and J. Holguín-Veras, "Agent-based simulation model for evaluating urban freight policy to e-commerce," Sustainability (Switzerland), vol. 11, no. 15, p. 4020, 2019, doi: 10.3390/su11154020.

[12] V. W. Zheng et al., "Heterogeneous Embedding Propagation for Large-Scale E-Commerce User Alignment," Proceedings - IEEE International Conference on Data Mining, ICDM, vol. 2018-Novem. IEEE, pp. 1434-1439, 2018, doi: 10.1109/ICDM.2018.00198.

[13] Y. Deng, W. Zhang, and W. Lam, "Opinion-aware Answer Generation for Review-driven Question Answering in E-Commerce," International Conference on Information and Knowledge Management, Proceedings. ACM, pp. 255-264, 2020, doi: $10.1145 / 3340531.3411904$.

[14] F.-V. Pantelimon, T. M. Georgescu, and B.-S. Posedaru, "The Impact of Mobile e-Commerce on GDP: A Comparative Analysis between Romania and Germany and how Covid-19 Influences the e-Commerce Activity Worldwide," Informatica Economica, vol. 24 , no. $2 / 2020$, pp. $27-41,2020$, doi: $10.24818 /$ issn14531305/24.2.2020.03.

[15] C. Bozzi, M. Neves, and C. Mont'Alvão, “The 'Pandemic Effect' on e-Commerce," Lecture Notes in Networks and Systems, vol. 319. Springer International Publishing, pp. 532-540, 2022, doi: 10.1007/978-3-030-85540-6_67.

[16] Q. Ding and H. Zhao, "Study on e-commerce logistics cost control methods in the context of COVID-19 prevention and control," Soft Computing, vol. 25, no. 18, pp. 11955-11963, Sep. 2021, doi: 10.1007/s00500-021-05624-5.

[17] B. FitzHerbert, "Saudi Arabia turns to e-commerce during Covid-19 outbreak," LogisticsGulf, pp. 1-5, Apr. $01,2020$.

[18] H. N. Alkhaldi, "Legal Challenges Of E-Commerce In Kuwait During The Covid-19 Pandemic," Information \& Security: An International Journal, p. 125, 2020, doi: 10.54032/2203-008-998-002.

[19] M. A. Salem and K. Md Nor, "The Effect Of COVID-19 On Consumer Behaviour In Saudi Arabia: Switching From Brick And Mortar Stores To E-Commerce," International Journal of Scientific \& Technology Research, vol. 9, no. August, p. 7, 2020, [Online]. Available: www.ijstr.org.

[20] K. Sharma, "A Surge in E-Commerce Market in India After Covid-19 Pandemic," Gap Gyan a Global Journal of Social Sciences, vol. III, no. IV, pp. 54-57, 2020, [Online]. Available: https://www.gapgyan.org/.

[21] R. S. D. Al-Tayyar, A. R. Abdullah, A. A. Rahman, and M. H. Ali, "Challenges and obstacles facing SMEs in the adoption of ecommerce in developing countries: A case of Saudi Arabia," Estudios de Economia Aplicada, vol. 39, no. 4, 2021, doi: 10.25115/eea.v39i4.4644.

[22] "The Management of E-Commerce in the Kingdom of Saudi Arabia: An Exploratory Research," European Journal of Business and Management, 2020, doi: 10.7176/ejbm/12-6-13.

[23] T. A. Habboush and B. F. Alanazi, "The Impact of Electronic Commerce on Motivating the Investment in the Kingdom of Saudi Arabia," Journal of International Business Research and Marketing, vol. 5, no. 5, pp. 13-27, 2020, doi: 10.18775/jibrm.18498558.2015.55.3002.

[24] B. Taneja, "The Digital Edge for M-Commerce to Replace E-Commerce," Emerging Challenges, Solutions, and Best Practices for Digital Enterprise Transformation. IGI Global, pp. 299-318, 2021, doi: 10.4018/978-1-7998-8587-0.ch016.

[25] L. T. Khrais, "Investigation use of Social Media, Mobile Apps, and the impacts of Enlarging E-Commerece," 2020 6th International Conference on Advanced Computing and Communication Systems, ICACCS 2020. IEEE, pp. 1365-1372, 2020, doi: 10.1109/ICACCS48705.2020.9074341.

[26] R. Pang, "The growth of payment apps like Alipay, Apple Pay, and WeChat Pay in two major markets, the risks and the benefits, and the relations with traditional finance," WIRE - Wenzhou-Kean University Intellectual Research Environment, 2020.

[27] Statista Research Department, Number of mobile phone internet users in Saudi Arabia from 2015 to 2025(in millions), Statista, 2021. Accessed: June 21, 2021. [Online]. Available: https://www.statista.com/statistics/558821/number-of-mobile-internet-userin-saudi-arabia/

[28] M. P. Johnston, "Secondary Data Analysis: A Method of which the Time Has Come," Qualitatve and Quantative Methods in Libraryes (QQML), vol. 3, no. 3, pp. 619-626, 2014

[29] V. Braun and V. Clarke, "One size fits all? What counts as quality practice in (reflexive) thematic analysis?," Qualitative Research in Psychology, vol. 18, no. 3, pp. 328-352, 2021, doi: 10.1080/14780887.2020.1769238.

[30] M. E. Kiger and L. Varpio, "Thematic analysis of qualitative data: AMEE Guide No. 131," Medical Teacher, vol. 42, no. 8, pp. 846-854, 2020, doi: 10.1080/0142159X.2020.1755030.

[31] L. Adrian, L. M. Little, and C. B. Royeen, "Objects of Sleep: A Graphical Analysis," Annals of International Occupational Therapy, vol. 4, no. 4, 2021, doi: 10.3928/24761222-20210601-06.

[32] P. C. Terry, R. L. Parsons-Smith, and V. R. Terry, "Mood Responses Associated With COVID-19 Restrictions," Frontiers in Psychology, vol. 11, p. 589598, Nov. 2020, doi: 10.3389/fpsyg.2020.589598. 
[33] D. A. Alzahrani and M. A. Al-Dabbagh, "Attitudes towards the e-shopping for ready-made clothing in Saudi Arabia an analytical study of Yanbu Governorate," International Design Journal, vol. 10, no. 1, pp. 95-102, 2020.

[34] L. T. Khrais, "Role of artificial intelligence in shaping consumer demand in e-commerce," Future Internet, vol. 12, no. 12, pp. 114, 2020, doi: 10.3390/fi12120226.

[35] "Middle East consumer behaviour changing and shifting online," Consultancy-me.com. https://www.consultancyme.com/news/2957/middle-east-consumer-behaviour-changing-and-shifting-online.

[36] K. Tiwari, "Rising kingdom of ecommerce: post-COVID online retail trends in Saudi Arabia," 2021. [Online]. Available: https://www.capillarytech.com/blog/capillary/ecommerce/ecommerce-in-saudi-arabia-growth-trends-opportunities-2/.

[37] S. S. Sharma, "A Note on the Asian Market Volatility During the COVID-19 Pandemic," Asian Economics Letters, 2020, doi: 10.46557/001c.17661.

[38] M. Mahmud, "Impact analysis of digital transformations on entrepreneurial ecosystem in the eastern province of Saudi Arabia," Journal of Entrepreneurship Education, vol. 23, no. 1, pp. 1-15, 2020, [Online]. Available: https://search-proquestcom.proxy.library.dmu.ac.uk/docview/2425599591/fulltextPDF/75D4482ADDD6481EPQ/1?accountid=10472.

[39] M. Jan, Y. C. Rizwan, and T. Brahimi, "Covid-19 Impact on the Economy of Saudi Arabia," ... Journal of Archaeology of ..., vol. 18, no. 13, pp. 1406-1419, 2021.

[40] Q. Zhong et al., "Financial Defaulter Detection on Online Credit Payment via Multi-view Attributed Heterogeneous Information Network," The Web Conference 2020 - Proceedings of the World Wide Web Conference, WWW 2020. ACM, pp. 785-795, 2020, doi: 10.1145/3366423.3380159.

[41] H. S. Chasib, S. R. Salih, and I. J. K. Al-Ogaili, "An adaptive multi-hop routing with IoT abstraction for minimizing delay-node capacity trade-offs in mobile ad-hoc network," International Journal of Electrical and Computer Engineering, vol. 11, no. 6, pp. 5315-5326, 2021, doi: 10.11591/ijece.v11i6.pp5315-5326.

[42] M. O. Adebiyi, R. O. Ogundokun, A. I. Nathus, and E. A. Adeniyi, "Smart transit payment for university campus transportation using RFID card system," International Journal of Electrical and Computer Engineering, vol. 11, no. 5, pp. 4353-4360, 2021, doi: 10.11591/ijece.v11i5.pp4353-4360.

[43] M. D. A. Rahman, M. S. Hossain, N. A. Alrajeh, and B. B. Gupta, "A multimodal, multimedia point-of-care deep learning framework for COVID-19 diagnosis," ACM Transactions on Multimedia Computing, Communications and Applications, vol. 17, no. 1s, pp. 1-24, 2021, doi: 10.1145/3421725.

[44] S. Jha, M. K. Goyal, B. Gupta, and A. K. Gupta, "A novel analysis of COVID 19 risk in India incorporating climatic and socioeconomic Factors," Technological Forecasting and Social Change, vol. 167, p. 120679, Jun. 2021, doi: 10.1016/j.techfore.2021.120679.

\section{BIOGRAPHIES OF AUTHORS}
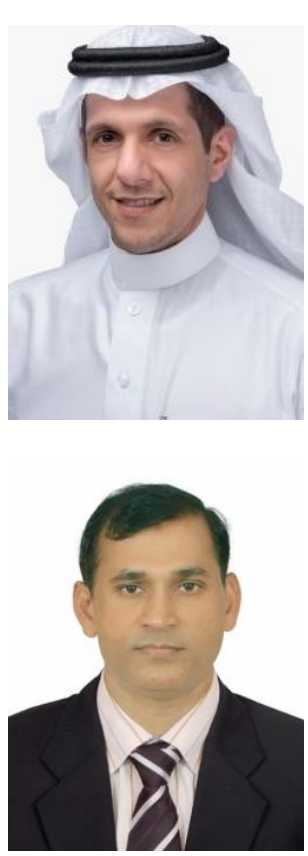

Abdulmohsin Suliman Alkhunaizan (iD $8 \mathrm{SC}$ SC is currently serving as an assistant professor at Majmaah University in the department of Information Systems and Computer Science. He is also serving as a Dean of PYP program of Majmaah University. He holds a $\mathrm{PhD}$ in information system, Brunel University UK. His research interests include MCommerce, E-Learning and Mobile social network use. He can be contacted at email: a.alkhunaizan@mu.edu.sa.

Ashraf Ali (iD 81 SC P is an Assistant Professor at the Faculty of Computer Studies, Arab Open University, Kingdom of Bahrain. He holds a Ph.D. degree in Computer Science and Engineering. He has 14+ years of experience in teaching at various universities around the world including Saudi Arabia, Yemen, Oman, and Bahrain. His research interest includes Cloud Computing, Web Mining, Web Information Retrieval, Semantic Web, Semantic Similarity, and Artificial Intelligence. He has published several articles in various journals of repute. He can be contacted at email: ashraf.ali@aou.org.bh. 